\title{
Estimation of Construction Duration for Roads and Bridges in Nepal
}

\author{
Prakriti Pokhrel ${ }^{a}$, Jibendra Misra ${ }^{b}$, Dikshit Babu Nepal ${ }^{c}$, Pradip Adhikari ${ }^{d}$ \\ a Masters Research Scholar, Pokhara University, Nepal \\ b Senior Divisional Engineer, Department of Roads, Government of Nepal \\ c PhD Research Scholar, University of Sydney, Australia \\ d Master Research Scholar, Shanghai JiaoTong University, China \\ Corresponding Email: a dor.prakriti@gmail.com
}

\begin{abstract}
Precise estimation of contract duration is a tough job in the construction field given the uncertainties involved in it. The construction industry for Roads and Bridges in Nepal is in a transitional phase and the working procedures varies on the individual capacity of each contractor. So, a practical approach is necessary for developing a methodology for estimation of duration. At present the estimated contract duration lacks uniformity among the projects of similar size and nature. With time extension issue getting much attention in recent amendments of PPR, estimation of duration has yet in the shadows among the lawmakers. This research aims at developing an empirical formulae for determination of contract duration based on the historical data of roads and bridges completed within the last five years. A total of 83 bridges and 78 road projects were analyzed. Regression analysis was carried out for developing a mathematical relation between time and cost of the project. The data was made to fit in Browmillow's time-cost model. Apart from the cost of the project, there are other factors that affect the duration of the project. To address these project specific requirements, modification were recommended to the time-cost model by introducing coefficients in the empirical relation. As per the obtained equation, contract duration is directly proportional to the cost. However, the rate of increase in contract duration decreases with increase in cost. The reason for this is due to the higher level of parallel activities and better use of technologies for the contracts with higher cost. This model can be useful for government agencies, contractors and consultants involved in construction and procurement of roads and bridges in Nepal. The empirical formula obtained as an outcome of this research is applicable for roads and bridge projects of Nepal with estimated amount greater than two crore.
\end{abstract}

\section{Keywords}

Estimation of contract duration, Duration Prediction, Browmillo's time cost model (BTC), Time cost model, BTC for roads and bridges

\section{Introduction}

Construction projects are extensive works involving large number of varied activities. They involve uncertainties. These uncertainties arise from the nature of the work itself, construction sites, technologies used, manpower and even the overall socio-economic aspect of the nation as well. Amidst these unforeseeable conditions, appropriate estimation of contract duration for these projects is a tough task. For specific case of Nepal, where construction field itself is in a transitional phase, juggling in the duality of machines and manual works, it is even more a tough job to precisely estimate the construction duration. However, with the frequent changes in policies and regulations regarding the extension of time for the construction projects, it also seems like nation is somewhat experimenting and is in a trial and error phase in regards with the contract duration and its extension. Thus, a practical approach, rather than theoretical is necessary for the appropriate estimation of contract duration. Time is money. In construction business it is even more so as it involves a number of overhead charges. If the contract duration is unduly extended or overestimated it leads to unnecessary delays and the infrastructure cannot serve its stated purpose at the earliest. At the same time if the construction duration is under estimated, it leads to 
Table 1: Time Cost Models developed over the years (Ameyaw et al., 2012)

\begin{tabular}{|l|l|l|}
\hline Author(s) and Year of Study & Country & Type \\
\hline Bromilow (1969) & Australia & Building construction \\
Kaka and Price (1991) & UK & Building and Roads \\
Long and Dai Lee (2009) & Korea & Building construction \\
Endut et al. (2006) & Malaysia & Building construction \\
Ogunsemi and Jagboro (2006) & Nigeria & Construction Cost \\
Chen and Huang (2006) & Taiwan & School projects \\
Thomas Ng et al. (2001) & Australia & Building construction \\
Love et al. (2005) & Australia & Building construction \\
Kumaraswamy and Chan (1995) & HongKong & Building construction \\
Chan (1999) & Hong Kong & Building construction cost \\
Mensah (2010) & Ghana & Feeder Roads \\
\hline
\end{tabular}

unnecessary paper works for time extension and can often be the cause of the conflict between the client and the contractor.

No project can kickstart without estimation of duration. Estimation of construction duration is a key aspect for project scheduling, inventory management, financial planning and for the overall planning of construction and administrative activities for a project. In construction contracts, the provision of bonuses for contractors who finish works earlier or imposition of penalty for those delaying the works could be provisioned if an objective method of calculation of project time is available. It is true that no scientific method and scheduling technique is being applied in the present scenario in Nepal for determining the contract period necessary for the completion of the projects. In the present context, the construction duration is largely the outcome of the personal judgment of the personnel involved in the procurement procedures due to which there exists a lack of uniformity in the estimation of contract duration.

\subsection{Research Objectives}

The objective of this research is to formulate an empirical relation for estimation of contract duration for roads and bridges projects in Nepal. The empirical relation is based on the Browmillow's time cost model. Different coefficients are introduced to address the work complexity and project specific issues in the context of Nepal.

\section{Literature Review}

\subsection{Contract Duration}

Construction Contract duration is the time or duration allocated for a construction work to complete all of its activities on a normal working condition at minimum rate and the prevalent work practices. This however, does not include the probable effects of force majure or accelerated work condition. The start date and completion date is usually agreed upon at the time of contract agreement itself. A system plan along with the commitment is required from all those involved in the construction for an appropriate control over the construction duration (McNulty, 1982). The overall process of planning and acquiring time frames for each activities within the project is refereed to as scheduling. It is an important part of the construction process and plays a vital role in budgeting and financial planning of the overall construction process (Peurifoy and Ledbetter, 1985, Kaka and Price, 1991). A precise pre-design estimation of contract duration can be very useful for both contractor and client in inventory and financial planning along with determination of cash flow and profitability of the project (Chan, 1999).

\subsection{Time Cost Model}

Time cost model are no new concept for the estimation of contract duration. Bromilow (1969), carried out a research for building projects in Australia, and is still considered to be the pioneer in the area. However, in the recent time, several studies have been carried out at different parts of the world for various branches of civil engineering. Researchers have tried to develop and interconnect the time and cost of construction project 
in building, roads, bridges, among others.

Kumaraswamy and Chan (1995) used variable like gross floor area, number of floors, estimated duration and cost of the project to derive a relation for project duration. Hoffman et al. (2007) gave a multivariate model for project time estimation. Jarkas (2016) also put forward a multivariate model, which he argued to be more accurate as compared with BTC. Apart from the statistical models, AAN (Artificial neural networks) have also been developed with advancement in the technologies in the recent times. Chen and Huang (2006) studied reconstruction projects of schools after earthquake, for which he developed a back-propagation neural network (BPNN) for time-cost estimation. Petruseva and Zileska-Pancovska (2013) developed multilayer perceptron neural network (MLP-NN) model for higher prediction accuracy of contract duration. Sun and $\mathrm{Xu}$ (2011) proposed the Elman neural network (EN) and argued that it showed better accuracy for time estimation to establish the time-cost prediction model for post-earthquake reconstruction project.

Some of the highlighted works in this area includes: Long and Dai Lee (2009), Le-Hoai et al. (2009), Hoffman et al. (2007). Works in africa includes Ogunsemi and Jagboro (2006) for Nigeria. Chen and Huang (2006) and Endut et al. (2006) worked in Taiwan and Malaysia respectively to develop a time cost model. Further studies include Bromilow and Henderson (1977), Bromilow et al. (1980, 1988), Sidwell (1984), Walker (1995), Thomas Ng et al. (2001), Love et al. (2005), Kumaraswamy and Chan (1995), Chan (1999), Kaka and Price (1991). Table 1 shows a list of works along with the country and area of civil engineering projects where time cost model had been developed.

\subsection{Browmilow's Time Cost Model}

Browmillow formulated an empirical relation based on the 883 historical data of building construction projects in Australia in 1969 and developed a model popularly called Bromilow's time-cost (BTC) model. The main objective of this model was to use the estimated project cost to predict the construction duration in a quick yet reliable manner. Browmillow's research highlighted that the project duration was highly dependent on the project cost (Bromilow, 1969). Linear Regression analysis was used for the development of the model. Various other researchers have tried and tested BTC in their respective work area. Hoffman et al. (2007) pointed that BTC was able to provide point estimate along with upper, lower quartile limits for estimation of construction duration.Hoffman et al. (2007) highlighted two major criticism over the BTC model. The first critisicm on the reliability of the data outside of the research area worked on by Browmillow. The second criticism was on the use of cost alone as a determining factor for estimation of construction duration. Both of these criticism have led to certain level of refinement on the model (Hoffman et al., 2007). Thomas $\mathrm{Ng}$ et al. (2001) also argued that, despite the above stated criticism, BTC still holds a recognition for being a widely used model for estimation of construction duration. Mensah (2010) adopted BTC for estimation of project duration in Ghana for donor funded road projects and ascertained its suitability for the project. in a bid to estimate project duration in Ghana, adopted the Bromilow's time cost model and found that it is applicable to donor funded feeder roads projects in Ghana. Long and Dai Lee (2009) used the time cost model for historical building projects in Korea and concluded its applicability.

It can be concluded that BTC holds a good position for time- cost relation.BTC is also widely used for its simplicity. Predictive model based on a historical data requires amendment and modification after a certain duration. With BTC, the reconstruction and modification process too becomes much simpler. However, for determination of contract duration, more dependent parameters like geography, vehicle accessibility, nature of projects etc also plays a vital role, and hence further project specific modification on BTC can make the estimated duration more accurate and precise.

Browmillow's time cost model (Bromilow, 1969) is expressed in equation 1 .

$$
T=K \times C^{B}
$$

Here,

$T=$ project duration

$C=$ Actual cost of the project including fluctuations and variations

$K=$ a constant showing the level of time performance for unit cost

$B=$ a constant describing how the time performance was affected by project size as measured by the cost. 
Table 2: Population of data

\begin{tabular}{|c|l|c|}
\hline S.N & Construction Projects & Number of data \\
\hline 1 & Roads & 78 \\
2 & Bridges & 83 \\
\hline
\end{tabular}

Table 3: Regression statistics for Bridges and Roads

\begin{tabular}{|c|l|c|}
\hline Regression Parameters & \multicolumn{2}{|c|}{ Value } \\
\hline $\mathrm{n}$ & 83 & 78 \\
$\Sigma \mathrm{Y}$ & 507.36 & 479.08 \\
$\Sigma \mathrm{X}$ & 540.86 & 583.40 \\
$\Sigma \mathrm{XY}$ & 3316.36 & 3603.59 \\
$\Sigma Y^{2}$ & 3105.19 & 2950.78 \\
$\Sigma X^{2}$ & 3571.87 & 4457.58 \\
\hline
\end{tabular}

\subsection{Present practise of contract estimation in Nepal}

Public tendering on construction in Nepal is governed by "Public Procurement Act 2007 (PPA) and Public Procurement Regulation 2007" (PPR) in Nepal. There is provision of "duration to be mentioned while preparing the cost estimate" in rule 9 of the Regulation but this provision does not state the methods of determining the construction contract duration (CCD). Also, in the period of two year there has been four amendments in the PPR and one amendment on PPA is already under discussion. Each of these amendments have included the topic of Extension of time for construction duration. The provisions for EOT has been changing as if the nation is following a trial and error policy for EOT. With so much attention and experimentation on the EOT, little has been mentioned and formulated for the estimation of contract duration. As the provisions of EOT can't be effectively applied without uniformity in contract duration, the nation itself is in need of a guideline for estimation of contract duration.

In the context of Nepal, at present the method being applied till date to determine contract duration for construction projects is mostly ad-hoc, irrespective of geographic complexity, nature of work and the workable day considerations. Similarly the contract duration is inconsistent in different projects. No specific methods as bar chart or CPM are referred by the public entity on a usual basis. The past works or experience of particular officials involved in the procurement unit plays a vital role in determination of contract duration. No specific procedure or methodology has been suggested in PPA and PPR for the estimation. One of the Departments under Government of Nepal i.e. Department of Roads has published a methodology and formulae that can be consulted, for calculation of duration of time for construction works. However, that has not been updated since five years. The guideline published by DoR has been recommended as for guidance purpose only and not to be referred to as a cookbook recipe for time calculation. So, the use of empirical relation has not been made mandatory and the ultimate decision for time determination is put on the procurement agency itself.

\section{Methodology}

This research followed a quantitative and analytical approach to formulate a empirical equation based on the Browmillow's time cost model for determination of project duration. Primary as well as secondary data was collected from various road division offices and projects in Nepal. Roads and Bridges with contract amount greater than two Crore and completed within the fiscal year 2069/70 were only considered for the research. The currency used for the research was Nepalese rupees. (NRs) and the unit of cost for the formulae is $1 \mathrm{Lakh}$. The population of each roads and bridges considered for the study is presented in 2 . The data analysis was done using the graphical tool software. Origin was used to develop equations and prepare graphs. The raw data collected from primary and secondary sources were fined up and clustered using MS excel. Regression analysis was used for initial development of equation using Ms excel.

Regression Analysis was carried out for data of bridges as well as roads to project the data into linear equation. As per the Browmillow's Time cost model, the time or duration of contract is given by equation 1 .

\subsection{Data Collection and Sampling}

The study comprised of heterogeneous population. Due to the restricted conditions for requirement of the study (e.g. construction cost greater than 2 crore and completion of project within the last five fiscal years), and lack of ideal data management system in respective governmental agencies, the population size itself was limited. In order to obtain as many data as possible, samples were selected on the basis of availability of data from the governmental agencies. However, from statistical point of view for regression analysis, a minimum of 10 sample size per variable 
Table 4: The Research Reviews of BTC Model (Guo and Chang-Ming Bao, 2019)

\begin{tabular}{|l|l|l|l|l|}
\hline Author(s) and Year of Study & Country & Type & $R^{2}$ & BTC model \\
\hline Bromilow (1969) & Australia & Building construction & - & $T=177 C^{0.3}$ \\
Bromilow and Henderson (1977) & Australia & Building construction & - & $T=313 C^{0.3}$ \\
Kaka and Price (1991) & UK & Civil engineering projects & - & $T=291 C^{0.205}$ \\
Kaka and Price (1991) & UK & Road construction & - & $T=301.4 C^{0.215}$ \\
Kumaraswamy and Chan (1995) & Hongkong & Public buildings & - & $T=188.7 C^{0.259}$ \\
Kumaraswamy and Chan (1995) & Hongkong & Private buildings & - & $T=206.5 C^{0.2}$ \\
Kumaraswamy and Chan (1995) & Hongkong & Civil works & - & $T=250.5 C^{0.206}$ \\
Hoffman et al. (2007) & USA & Facility Projects & 0.337 & $T=26.8 C^{0.202}$ \\
Sun and Xu (2011) & China & Reconstruction buildings & 0.522 & $T=42.4 C^{0.286}$ \\
Ameyaw et al. (2012) & Ghana & Office & 0.682 & $T=344.59 C^{0.684}$ \\
Ameyaw et al. (2012) & Ghana & Classroom & 0.463 & $T=512.28 C^{0.463}$ \\
Ameyaw et al. (2012) & Ghana & Residual & 0.399 & $T=2.807 C^{0.399}$ \\
Jarkas (2016) & Kuwait & Residential Building & 0.803 & $T=28.79 C^{0.192}$ \\
Jarkas (2016) & Kuwait & Office Building & 0.849 & $T=7.92 C^{0.277}$ \\
\hline
\end{tabular}

has been recommended for use in regression analysis. The data collection included sample data from more than forty Road division Projects offices throughout the nation, which included sample data of all three major geographical regions (mountain, hill and terai). However, only the construction contract with cost greater than 2 crore and those completed within the last five years were included for the study. The bridges under study were of varying length, span and type (RCC,PSC).

Taking logarithmic on both sides,

$$
\operatorname{Ln}(T)=\operatorname{Ln}(K)+B \operatorname{Ln}(C)
$$

Also, the equaltion of linearity is,

$$
Y=A+B X
$$

Comparing corresponding quantities,

$$
Y=\operatorname{Ln}(T)
$$

Similarly,

$$
A=\operatorname{Ln}(K)
$$

Also,

$$
X=\operatorname{Ln}(C)
$$

Statistical Parameters obtained after regression analysis of data of 83 bridge and 78 Roads project is presented in Table 3 :-

The statistical parameters obtained from the regression analysis stated in Table 3 was used to determine the value of constants and to fit in the browmillow's time cost model.

\section{Results and Discussion}

\subsection{Linear Relationship of Data}

The statistical parameters obtained from the data was made to fit in the linear equation using regression analysis. The result of log-log regression for roads and bridge data is summarized: The coefficient of determination $\left(R^{2}\right)$ for bridge project is 0.58391 while that for road project is 0.52503 . This implies that $58.39 \%$ of variability in the bridge data and $52.50 \%$ of variability in the roads data is incorporated by the respective empirical relations.

There is no particular limiting value of $\left(R^{2}\right)$ on the basis of which the model can be judged. Higher value of $\left(R^{2}\right)$ indicates better predictability of the model. However, the value of $\left(R^{2}\right)$ in the range of 0.4 to 0.6 is considered to be acceptable in simple as well as multiple linear regression. The value of $\left(R^{2}\right)$ in case of BTC for various projects conducted worldwide have been shown in Table 4

The intercept value of 4.70969 is obtained in bridge and that in road is 4.52701 . This gives the value of constant $\mathrm{K}$ in the equation 5 which is 111.018 for bridge and 92.482 for road project. This value of $\mathrm{K}$ implies the number of days required for completion of project of unit cost (one lakh). 111.018 days for a bridge project and 92.482 days for roads projects are required for completion of work worth contract amount of 1 lakhs. However, this statement cannot be generalized as the model is made to suite only for amount greater than 2 crores. The slope intercept value of 0.21527 in bridge and 0.21593 in road indicates the 
Table 5: Summary of log-log regression of Bridge and Road data

\begin{tabular}{|c|l|c|l|c|l|}
\hline & \multicolumn{2}{|c|}{ Intercept } & \multicolumn{2}{c|}{ Slope } & Statistics \\
\hline & Value & Std. error & Value & Std. error & Adj. $R^{2}$ \\
\hline Bridge & 4.70969 & 0.13106 & 0.21527 & 0.01998 & 0.58391 \\
Road & 4.52701 & 0.1759 & 0.21593 & 0.02327 & 0.52503 \\
\hline
\end{tabular}

influence of size of project (measured by its cost) on the contract duration. Larger the value of slope intercept, larger is the influence of project size on the duration. The linear plot of log-log regression depicting $\ln$ ( Cost) vs $\ln$ (time) is shown in figure 1 Comparing the equation of Roads and bridges, the value of $\mathrm{K}$ is larger for bridges than for roads, which implies that longer time is required for bridge project than that for road for unit cost. The value of slope intercept, is higher for roads with slight difference than that of bridges. Larger value of slope intercept indicates greater influence of cost on the duration. From figure 1 and figure 2, it can also been seen that the degree of variability in road projects is higher than that in bridge project.

\subsection{BTC Model}

The output of the regression analysis in the form of Browmillow's time cost model for bridge projects and road projects is presented in equation 7 and 8 respectively.

For Bridge Project:-

$$
T=111.018 \times C^{0.2150}
$$

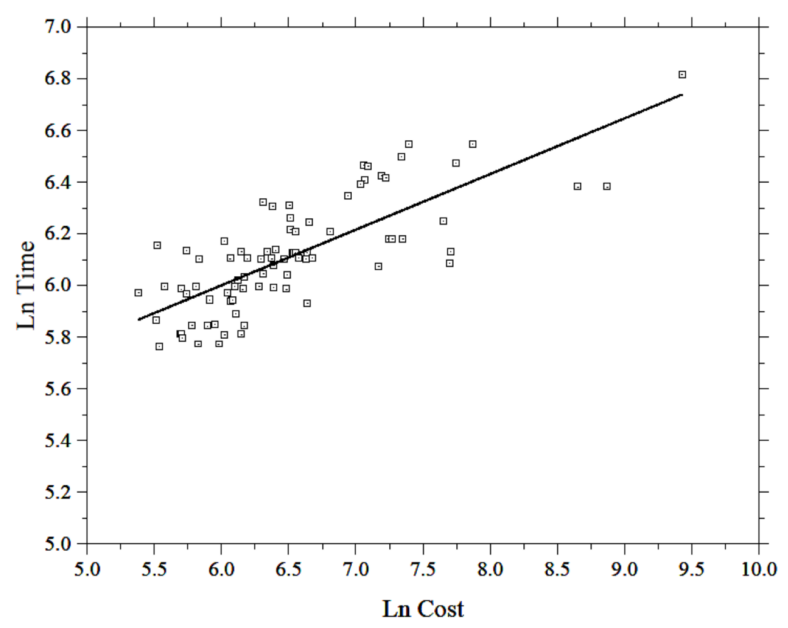

Figure 1: Linear Plot of log-log Regression for Bridge
For Road Project:-

$$
T=92.482 \times C^{0.2159}
$$

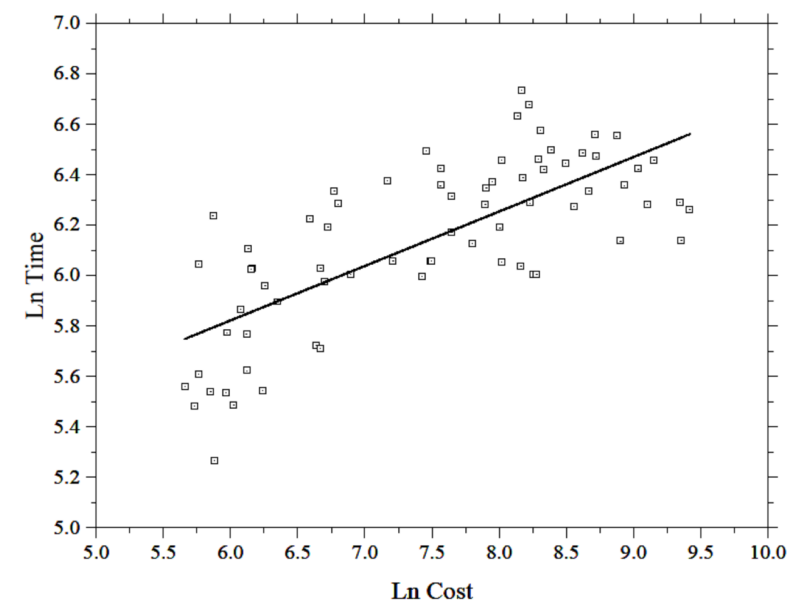

Figure 2: Linear Plot of log-log Regression for Road

The equation obtained in the form of time-cost relation was used to find the duration required for the historical data from which the empirical relation was derived. The actual time required for the project was compared with that of the time estimated from the time cost model. The summary of deviation between the actual and predicted duration is presented in table 6. Higher deviation is observed in the road projects than that in bridge.

Table 6: Summary of model predictive deviation for Bridge and Road

\begin{tabular}{|c|l|c|l|}
\hline Deviation & Max. & Min. & Avg \\
\hline Bridge & $32.48 \%$ & $-22.54 \%$ & $1.03 \%$ \\
\hline Road & $69.70 \%$ & $-35.84 \%$ & $2.51 \%$ \\
\hline
\end{tabular}

\section{Conclusion and Recommendation}

Time cost model is a simple yet effective way to deal with the uncertainties that comes in the procurement processes in the estimation of construction duration. This model can easily be reconstructed with new data along the span of time. With changes in technologies 
and work culture, the time required for the prediction of construction duration also changes. With this model, and with proper data on construction duration and cost, the time cost model can be regenerated.Such models enables quick determination of approximate project duration and can bring uniformity in the project duration provided. Since the model is based on historical data, the predictability of the model is valid only as long as the nature of work is similar to the data from which the model has been constructed. This research has been explicitly based on roads and bridges projects. Further study can be conducted on various other emerging sectors such as railroad, tunnel airport, pipelines, flyovers, large size buildings, and other infrastructures to develop similar models. On a larger level, the governmental agencies can enhance the historical data management system to develop such models for each sectors. Also, Necessary project specific modifications enable the estimator to determine more precise duration for the project.

\subsection{Project specific estimation of duration in calender days}

The output of the time cost model is in the working days and is generalized for all kind of project.The conversion of the working days into calender days is required. Also, the generalized empirical relation requires consideration of project specific aspects for higher accuracy and practical usability. Following aspects have been recommended for making the empirical relation more useful and practical:

1. Based on the present working practice in construction industry, out of the 365 days in a year, the non-working days include:

- Half of the Saturdays throughout the year:- 26

- Monsoon and explicit weather conditions:- 75 days

- Public and regional holidays and festivals:29

Thus the total of above days is 130 days, that is. 235 working days in a year. So, the conversion factor for working days to calender days can be considered as $235 / 365=0.6438$

2. The whole of the geographical terrain of Nepal needs to be grouped on the basis of vehicular access and ease of working conditions, as all the areas are not at the same level of ease. More developed cities have better working conditions and rural areas require more time than the developed. As per the specific condition in case of Nepal and for roads and bridges, following classification is proposed for addressing the coefficient for ease of terrain and working conditions.

Table 7: Value of Coefficient $\mathrm{C} 1$ for vehicle accessibility and construction environment.

\begin{tabular}{|l|c|c|}
\hline Vehicle accessibility & Grade & Coefficient (C1) \\
\hline Very Difficult & A & 1.20 \\
Difficult & B & 1.1 \\
Medium & C & 1.05 \\
Easy & D & 1.0 \\
\hline
\end{tabular}

- Grade A: Taplejung, Shankhuwasabha, solukhumbu, Lamabagar and Rolwaling area of Dolakha district, Manang, Mustang, Rolpa, Rukum, Humla, Jumla, Kalikot, Mugu and Dolpa, Jajarkot, Bajhang, Bajura, Darchula

- Grade B: Panchthar, Bhojpur, Terhathum, Okhaldhunga, Khotang, Regions of Dolakha except Lamabagar and Roling, Okhaldhunga, Khotang, Ramechhap, Rasuwa, Arghakhanchi, Gulmi, Myagdi, Parbat, Baglung, Salyan, Pyuthan, Doti, Acchham, Dadeldhura, Baitadi, Dailekh.

- Grade C: Illam, Dhankuta,Udaypur, Sindhuli, Sindupalchowk, Tanahu, Syanjha, Gorkha, Lamjung, Palpa, Dang, Bardiya, Surkhet, Kailali, Kanchanpur.

- Grade D: Jhapa, Morang, Sunsari, Saptari, Siraha, Dhanusa, Mahottari, Sarlahi, Nuwakot, Kavrepalanchowk,Bara, Parsa, Rautahat, Chitwan, Makwanpur, Kaski, Rupandehi, Nawalparasi, Kapilvastu, Banke, Kathmandu, Bhaktapur, Lalitpur.

3. Not all the works are of same category, even for roads and bridges, the complexity of work varies and it plays a vital role in the contract duration. A coefficient $\mathrm{C} 2$ is recommended for that, whose value may range from 0.9 to 1.1 , depending on the nature of the work. This coefficient is solely on the judgment, requirements and understanding of the procurement agency and personnel. I recommend that the $10 \%$ variation in contract duration should be should be allocated for self understanding of the engineer or procurement personnel or the authority who approves the estimate.

4. The formulae developed from this research is based on the time cost model, that is. The contract duration is based on the estimated amount. The cost however is a dynamic and variable component 
due to the ever going economic inflation and deflation. For e.g. The same $20 \mathrm{~m} \mathrm{RCC}$ bridge which would cost 5 lakh in $\mathrm{F} / \mathrm{Y}$ 2070/71, now might costs 10 lakhs in $\mathrm{F} / \mathrm{Y}$ 2076/77. To incorporate this factor, I recommend to use the NRB index value published by Nepal Rastra Bank. The base index shall be taken as that of $\mathrm{F} / \mathrm{Y}$ 2019/20 (Feb). So, when the formula is to be used in future, the increase in cost can be adjusted accordingly.

The formula recommended after project specific modifications is:

For Bridge Projects:

$$
T=\frac{I}{I_{0} \times 0.64} C_{1} \times C_{2} \times 111.018 \times C^{0.2150}
$$

For Road Projects:

$$
T=\frac{I}{I_{0} \times 0.64} C_{1} \times C_{2} \times 92.482 \times C^{0.2159}
$$

$\mathrm{T}=$ Contract Duration in Calender days.

$\mathrm{I}=$ Present /Latest NRB index Value.

Io= NRB index value of F/Y 2019/20 (Feb).

$\mathrm{C} 1=$ Coefficient for vehicle accessibility and construction environment.

$\mathrm{C} 2=$ Coefficient for complexity of work.

$\mathrm{C}=$ Cost of Construction work in Lakhs in Nrs.

\section{References}

Collins Ameyaw, Sarfo Mensah, and Yarhands Dissou Arthur. Applicability of bromilow's time-cost model on building projects in ghana. In Proc 4th West Africa Environment Research Conference, Abuja, Nigeria, pages 881-888, 2012.

FJ Bromilow. Contract time performance expectations and the reality. In Building forum, volume 1, pages 70-80, 1969.

FJ Bromilow and JA Henderson. Procedures for reckoning and valuing the performance of building contracts. Division of Building Research, CSIRO, 1977. ISBN 0643020578.

FJ Bromilow, MF Hinds, and NF Moody. Aiqs survey of building contract time performance. The Building Economist, 19(2):79-82, 1980.
FJ Bromilow, MF Hinds, and NF Moody. The time and cost performance of building contracts 1976-1986. Australasian Institute of Quantity Surveyors, 1988.

Albert PC Chan. Modelling building durations in hong kong. Construction Management and Economics, 17(2):189-196, 1999. ISSN 0144-6193.

Wei Tong Chen and Ying-Hua Huang. Approximately predicting the cost and duration of school reconstruction projects in taiwan. Construction management and Economics, 24(12):1231-1239, 2006. ISSN 0144-6193.

Intan Rohani Endut, Akintola Akintoye, and John Kelly. Relationship between duration and cost of malaysian construction projects. In Proceedings of the International Conference in the Built Environment in the 21st Century (ICiBE 2006), Kuala Lumpur, June, pages 299-309. Citeseer, 2006.

Jian-Xia Hu Guo and Rong Chang-Ming Bao. Predicting the duration of a general contracting industrial project based on the residual modified model. Journal of Civil Engineering, 23(8):32753284, 2019.

Greg J Hoffman, Alfred E Thal Jr, Timothy S Webb, and Jeffery D Weir. Estimating performance time for construction projects. Journal of Management in Engineering, 23(4):193-199, 2007. ISSN 0742597X.

Abdulaziz M Jarkas. Predicting contract duration for building construction: Is bromilow's time-cost model a panacea? Journal of Management in Engineering, ASCE, 32(1):05015004, 2016. ISSN 0742-597X.

Ammar Kaka and Andrew DF Price. Relationship between value and duration of construction projects. Construction Management and Economics, 9(4): 383-400, 1991. ISSN 0144-6193.

Mohan M Kumaraswamy and Daniel WM Chan. Determinants of construction duration. Construction Management and Economics, 13(3): 209-217, 1995. ISSN 0144-6193.

Long Le-Hoai, YD Lee, and Jeong Wook Cho. Construction of time-cost model for building projects in vietnam. Korean Journal of Construction Engineering and Management, 10(3):130-138, 2009. 
Le-Hoai Long and Young Dai Lee. Time-cost model of building construction projects in korea. Journal of Construction Engineering and Management (ICEM), 27(13/14):549-559, 2009.

Peter ED Love, Raymond YC Tse, and David J Edwards. Time-cost relationships in australian building construction projects. Journal of construction engineering and management, 131(2): 187-194, 2005. ISSN 0733-9364.

Alfred P McNulty. Management of small construction projects. McGraw-Hill Companies, 1982.

I Mensah. Estimating duration for road construction projects in ghana. The Ghana Surveyor, 3(1):45-58, 2010.

DR Ogunsemi and GO Jagboro. Time-cost model for building projects in nigeria. Construction management and economics, 24(3):253-258, 2006. ISSN 0144-6193.

Vahida Petruseva, Silvana Zujo and Valentina ZileskaPancovska. Neural network prediction model for construction project duration. International Journal of Engineering Research and Technology, 2(11): 1646-1654, 2013.

Robert Leroy Peurifoy and William Burl Ledbetter. Construction planning, equipment, and methods. Report, 1985.

AC Sidwell. The time performance of construction projects. Architectural Science Review, 27(4):8591, 1984. ISSN 0003-8628.

C. Sun and J. Xu. Estimation of time for wenchuan earthquake reconstruction in china. Journal of Construction Engineering and Management, 137 (3):179-187, 2011.

S Thomas Ng, Michael MY Mak, R Martin Skitmore, Ka Chi Lam, and Mark Varnam. The predictive ability of bromilow's timecost model. Construction management and Economics, 19(2):165-173, 2001. ISSN 0144-6193.

Derek HT Walker. An investigation into construction time performance. Construction Management and Economics, 13(3):263-274, 1995. ISSN 0144-6193. 
